\title{
DC-DC CONVERTERS: A REVIEW AND COMPARISON OF TOPOLOGIES FOR PV APPLICATION
}

\author{
R.Felshiya Rajakumari, Assistant Professor \\ Department of Electrical and Electronics Engineering \\ Karpagam Institute of Technology \\ Coimbatore, India
}

\begin{abstract}
Photovoltaic power generation systems have gained attention all over the world because of its availability, cleanliness, low maintenance cost and inexhaustible nature. But the output voltage from $P V$ is very low; hence a DC-DC step-up converter is employed. Selection of proper DC-DC converter with reduced output voltage ripple is also an important factor as it has an impact on the overall performance of PV system. This paper analyzes three different converters and a particular topology is chosen for PV applications. Further, ripple reduction topologies are proposed and the performance of DC-DC converter is analyzed in terms of output voltage ripple. Simulation studies of the topologies of DC-DC converters are carried out in MATLAB/SIMULINK. The results are verified.
\end{abstract}

Keywords-Solar PV, DC-DC Converters, Ripple.

\section{INTRODUCTION}

Growing concerns about climatic change and global warming resulting from carbon emissions have pushed for more use of renewable energy sources such as solar photovoltaic (PV), wind, solar, thermal, etc.[1]. Nowadays, it is necessary to reduce the cost and increase the efficiency to make solar energy to be more useful [2]. As a result, many research works address the development of solar power system in recent years with improved performance. Power electronics converts electrical energy from one form to another, achieving high conversion efficiency of the solar PVpowered system [3] [4]. Since most of the consumer loads and storage elements use DC supply, DC-DC converters have gaining popularity.

In this paper, three different converters i.e., Boost Converter, SEPIC Converter and Non-Inverting Buck Boost Converter have been investigated for PV applications. Boost Converter is a simple step-up whose advantage is that the input current is continuous [5].Sepic Converter can be operated either in step up or step down mode. It has more number of storage devices and it is widely used in battery equipment [5]. A Buck Boost Converter operates in step-up or step-down mode operation and it is used for low and medium power application [6]. It also suffers from high switching stress because it is due to inverted output. In order to overcome these drawbacks, Non- Inverting Buck Boost (NIBB) Converter is presented in this paper. Non Inverting Buck Boost Converter produces an inverted output voltage.

The objective of this paper is to propose a suitable DC-DC converter for output voltage ripple reduction in $\mathrm{PV}$ applications. Simulation studies of the topologies are carried out in MATLAB/SIMULINK. The topology with reduced output voltage ripple is selected and interfaced with PV and the results are verified.

Section II presents the topologies of DC-DC converters. Section III discusses the ripple reduction topologies and the results are analyzed. Finally, Conclusion is discussed in Section IV.

\section{TOPOLOGIES OF DC-DC CONVERTERS}

A circuit that converts the DC voltage from one level to another is called DC - DC converter. It involves controlling of the average output voltage to a desired value. The output voltage regulation is achieved by varying the input and output power of the converter. The various applications of DC - DC converter includes regulated switched mode DC power supplies, cellular phones and laptop computers. . The different topologies of DC-DC converter are discussed below and their output voltage ripple is calculated.

\section{A. Boost Converter (BC)}

A boost converter is a DC-DC converter that has an output voltage greater than the input voltage. Fig. 1 shows the circuit topology of Boost converter. The modes of operation, design equations, specification of the boost converter are listed in the TABLE I. 


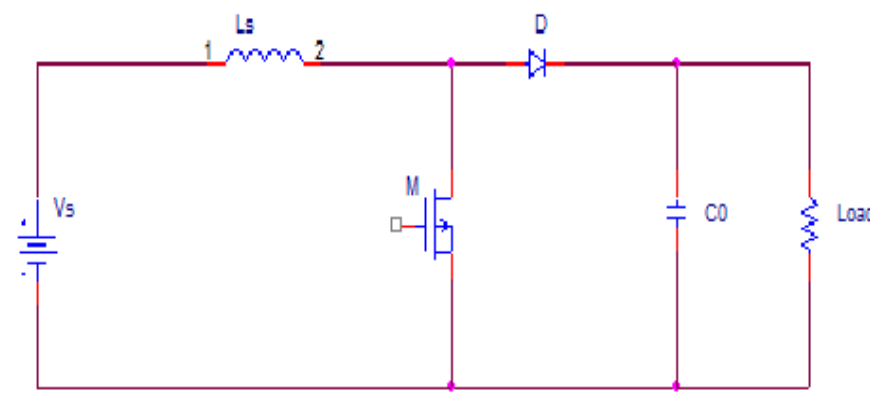

Fig. 1 Circuit Diagram of Boost Converter

The converter operates in two modes of operation. Fig. 2 shows the mode 1 and Fig. 3 shows the mode 2 operation.

Mode -1:

The circuit diagram for mode 1 operation is shown in Fig. 2. Mode 1 begins when the switch $\left(S_{1}\right)$ is turned on at $\mathrm{t}=\mathrm{t}_{\mathrm{on}}$. During on-time, the inductor current is greater than zero and it rises linearly. The output current during this interval is supplied from the output capacitor which is large enough to supply load current during on-time [7].

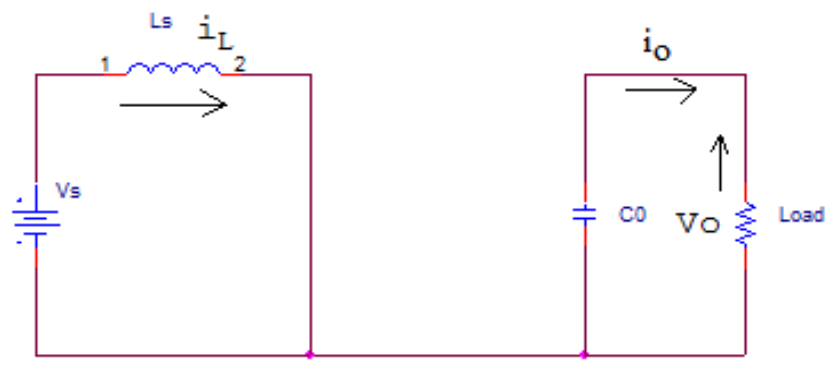

Fig. 2 Mode 1 Operation of Boost Converter

Mode -2:

Mode 2 begins when switch $\left(\mathrm{S}_{1}\right)$ is switched off at $\mathrm{t}=$ $\mathrm{t}_{\text {off. }}$ The circuit diagram for the mode 2 operation is shown in Fig. 3. The inductor current decreases until the switch is turned on again for the next cycle. In mode 2, operation the current will flow through the $\mathrm{C}, \mathrm{L}$ and load. The inductor delivers its stored energy to the load [7].

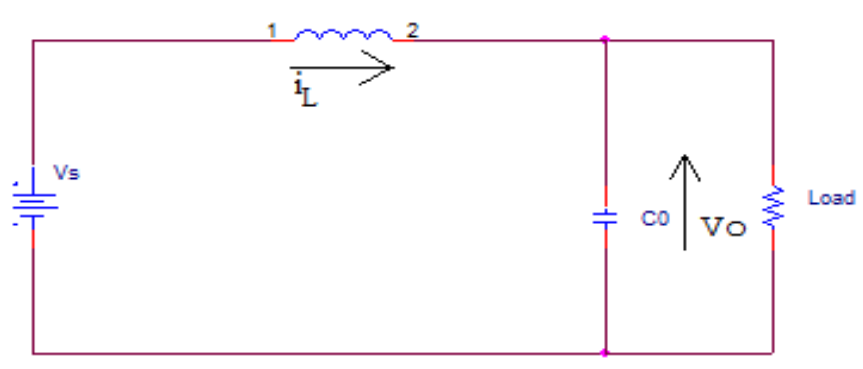

Fig. 3 Mode 2 Operation of boost converter

TABLE I. SPECIFICATION FOR THE BOOST CONVERTER

\begin{tabular}{|l|l|}
\hline \multicolumn{1}{|c|}{ Parameters } & \multicolumn{1}{c|}{ Values } \\
\hline Source voltage & $12($ volts $)$ \\
\hline Resistive Load & $100(\mathrm{ohm})$ \\
\hline Inductor & $60(\mu \mathrm{H})$ \\
\hline Capacitor & $500(\mu \mathrm{F})$ \\
\hline Switching frequency & $100(\mathrm{KHz})$ \\
\hline
\end{tabular}

Design Equations for Boost Converter:

The conversion gain for the boost converter is given in Eq. (1)

$$
V_{0}=\frac{V_{s}}{1-D}
$$

where $V_{s}$ the source voltage, D is the duty cycle for the boost converter, $V_{o}$ is the output voltage.

Boost inductance is selected based on the maximum allowable ripple current [8].

The peak to peak inductor current ripple is given as in Eq. (2)

$$
\Delta=\frac{V_{s} D}{f_{s} L}
$$

where, $\mathrm{L}$ is the inductor.

The peak to peak capacitor voltage ripple is given by Eq. (3)

$$
\Delta V_{c}=\frac{I_{s} D}{f_{s} C}
$$

where, $f s$ is the switching frequency, $\mathrm{C}$ is the Capacitor, $\Delta V_{c}$ is the peak to peak capacitor voltage.

\section{B. Single-Ended Primary Inductor Converter (SEPIC)}

Fig. 4 shows the circuit topology of SEPIC converter.

SEPIC converter is a type of DC-DC converter consisting of single-ended primary inductor. The output of the SEPIC converter is controlled by the duty cycle. It provides the positive regulated output voltage for the given input voltage. Isolation is provided by series coupling capacitor which protects the converter when short circuit occurs.

In steady state operation, the average voltage across capacitor $\mathrm{C}_{\mathrm{s}}$ is equal to the input voltage. The SEPIC converter operates in two modes of operations. The modes of operation are explained in detail [9], design equations are explained below and the specifications of the SEPIC converter are listed in TABLE II.

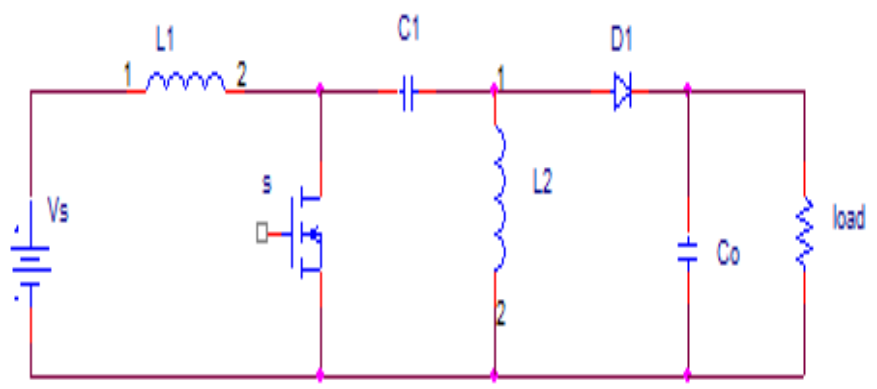

Fig. 4 Circuit Diagram of SEPIC Converter 
TABLE II. SPECIFICATION FOR THE SEPIC CONVERTER

\begin{tabular}{|l|l|}
\hline \multicolumn{1}{|c|}{ Parameters } & \multicolumn{1}{c|}{ Values } \\
\hline Source voltage & $12($ volts $)$ \\
\hline Resistive Load & $100(\mathrm{ohm})$ \\
\hline Inductor & $50(\mu \mathrm{H})$ \\
\hline Capacitor & $500(\mu \mathrm{F})$ \\
\hline Switching frequency & $100(\mathrm{KHz})$ \\
\hline
\end{tabular}

Design Equations for Sepic Converter:

The conversion gain for the SEPIC converter is given by Eq. (4)

$$
V_{0}=\frac{D^{*} V_{s}}{1-D}
$$

where, D is the Duty Cycle of the SEPIC Converter, $V_{0}$ is the output voltage and $V_{S}$ is the source voltage.

When the switch is turned on the inductor is charging the output current and then it is supplied to the output capacitor [9]. The output capacitor is given by Eq. (5)

$$
C_{0}=\frac{I_{0} * D}{V_{\text {ripple }}^{*} 0.5^{*} f s}
$$

where, $f_{s}$ is the switching frequency, $C_{0}$ is the output capacitor, ${ }^{V_{\text {ripple }}}$ is the peak to peak capacitor voltage ripple.

The inductor formula is given by Eq. (6)

$$
L=\frac{V_{s}}{\Delta L_{L}^{*} f_{s}} * D
$$

where, $\mathrm{L}$ is the Inductor, $\Delta L$ is the peak to peak inductor current ripple.

\section{Non-Inverting Buck Boost (NIBB) Converter}

A buck boost converter operates in step-up or step down mode but it suffers from drawbacks such as high switching stress due to inverted output, independent grounding of load and source side. In order to overcome these drawbacks the non-inverting buck boost converter is discussed in this section.

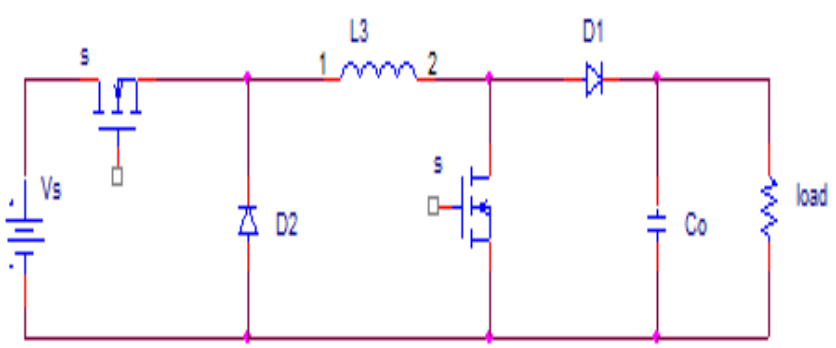

Fig.5 Circuit Diagram of NIBB Converter

Fig.5 shows the circuit diagram of non-inverting buck boost converter. The non inverting buck boost converter produces an output voltage that is of the same polarity as the input voltage. In buck mode the output voltage is determined by the operation of MOSFET $\left(S_{1}\right)$ and diode $\left(D_{1}\right)$. In boost mode, the output voltage is determined by the operation of MOSFET $\left(S_{2}\right)$ and diode $\left(D_{2}\right)$ [10]. The modes of operation, design equations of NIBB converter are discussed in Section A. The specification of the NIBB converter is given in TABLE I and the simulation results of the NIBB converter are shown below.

Simulation and Result Analysis of Different DC-DC Converters:

The different topologies of DC-DC converter operation is studied and analyzed in this section. The DC-DC converter has been simulated. The simulation has been performed in MATLAB/SIMULINK. Fig. 6 shows the simulation waveform of boost converter with a source voltage of $12 \mathrm{~V}$, Fig. 7 depicts the simulation waveform of sepic converter with a source voltage of $12 \mathrm{~V}$ and Fig. 8 depicts the simulation waveform of NIBB converter with a source voltage of $12 \mathrm{~V}$. Fig.9 depicts the output voltage ripple under different duty cycle for different DC-DC converters.

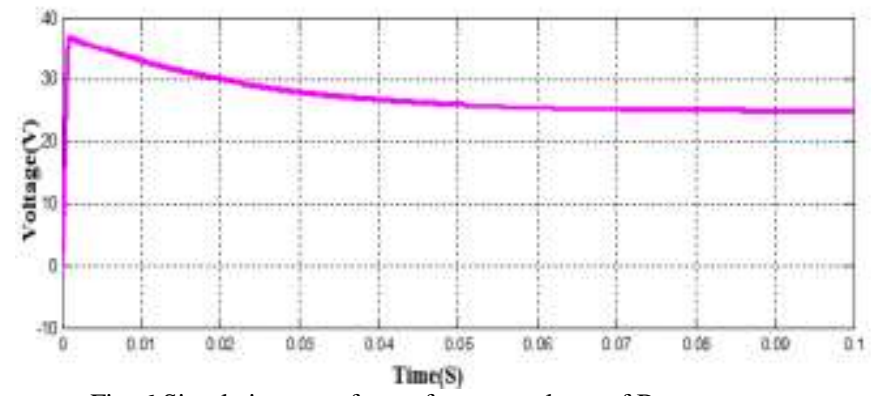

Fig. 6 Simulation waveform of output voltage of Boost converter

From Fig. 6, it is inferred that the output voltage of Boost Converter is $24 \mathrm{~V}$ with the given source voltage of $12 \mathrm{~V}$.

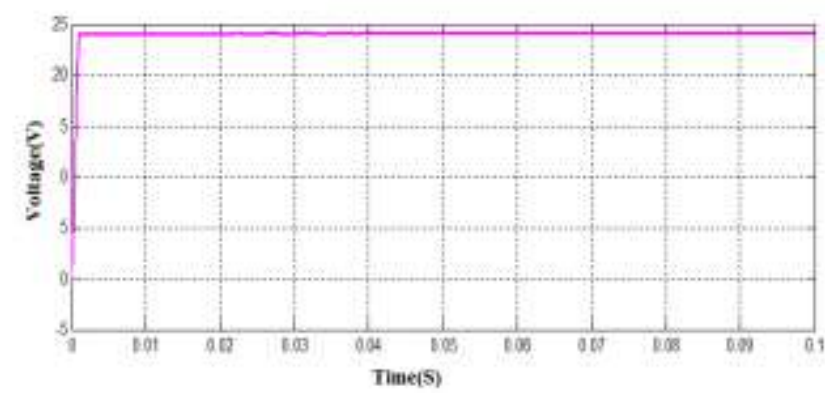

Fig. 7 Simulation waveform of output voltage of SEPIC Converter

From Fig. 7, it is inferred that the output voltage of Sepic Converter is $24 \mathrm{~V}$ with the given source voltage of $12 \mathrm{~V}$.

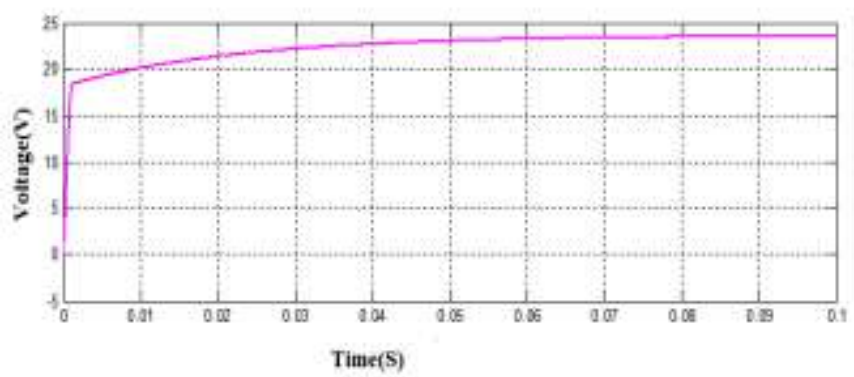

Fig.8 Simulation waveform of output voltage (Vout) of NIBB Converter 
From Fig. 8, it is inferred that the output voltage of NIBB Converter is $24 \mathrm{~V}$ with the source voltage of $12 \mathrm{~V}$.

From Figs. 6-8, output voltage ripple for different DC-DC converters have been calculated. Fig. 6 depicts the output voltage ripple for boost converter is $0.0025 \mathrm{~V}$. Fig. 7 show the output voltage ripple for sepic converter is $0.003 \mathrm{~V}$ and Fig. 8 depicts the output voltage ripple for non-inverting buck boost converter is $0.02 \mathrm{~V}$.

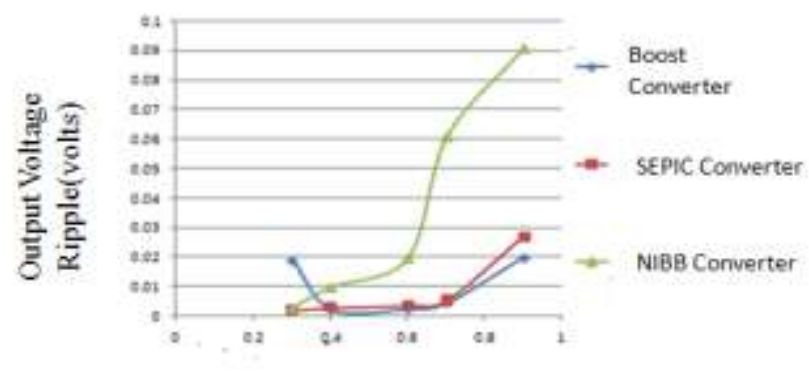

Duty Cycle

Fig. 9 Output Voltage Ripple Vs Duty Cycle for different DC-DC converters

Fig. 9 shows the variation of output voltage ripple with respect to the duty cycle for different DC-DC converters. It is inferred that the boost converter offers less output voltage ripple in comparison with other DC-DC converters

Fig. 10 shows the simulation of boost converter interfaced with PV. Fig. 11 shows the simulation waveform of output voltage for boost converter interfaced with PV.

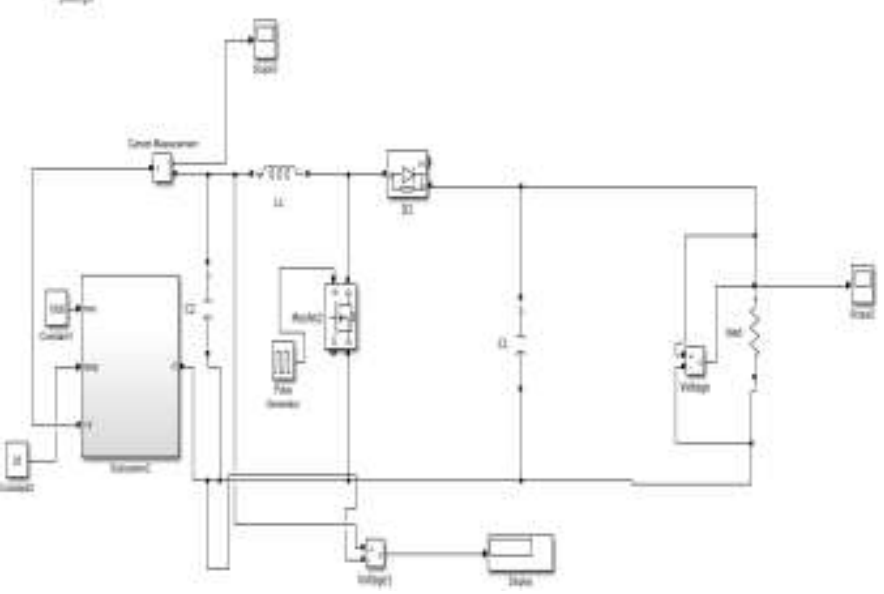

Fig. 10 Simulation of Boost Converter Interfaced with PV

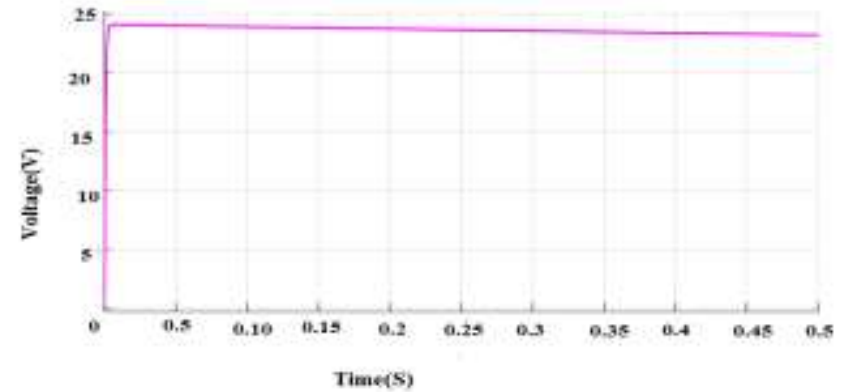

Fig. 11 Simulation waveform of output voltage of Boost Converter Interfaced with PV

From Fig. 11 it is inferred that the output voltage of Boost Converter interfaced with PV is 24 volts.

\section{RIPPLE REDUCTION TOPOLOGIES}

In this section, two topologies are explained briefly: Interleaved Boost Converter (IBC) and bidirectional Converter (BDC).

\section{Interleaved Boost Converter (IBC)}

Boost converter converts DC input voltage to a higher DC output voltage. But interleaving adds additional benefits to reduce the output voltage ripple and input current ripple. Fig. 12 shows the circuit diagram of two-phase Interleaved Boost Converter (IBC). Interleaved Boost Converter interfaced with $\mathrm{PV}$ and the simulation is carried out in MATLAB/SIMULINK.

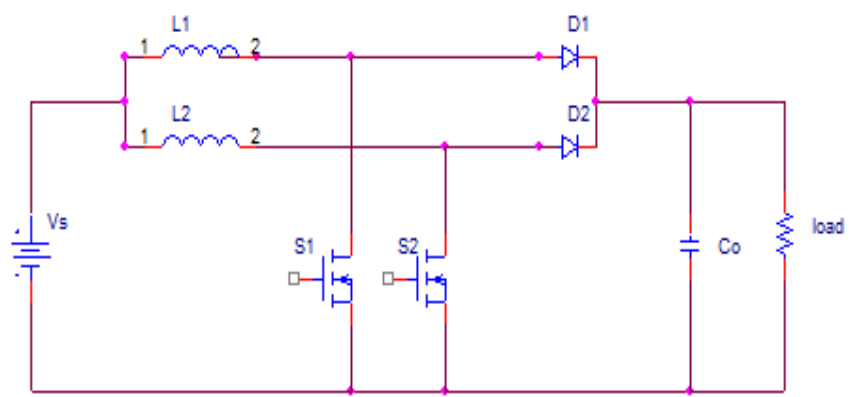

Fig. 12 Circuit Diagram of Interleaved Boost Converter

During $t_{o n}$, when $Q_{1 \text { is }}$ turned on, the current in the inductor $\mathrm{L}$ ramps upward. Therefore, the energy will be stored in the inductor $\mathrm{L}_{1}$. During $\mathrm{t}_{\mathrm{off}}$, when diode $\mathrm{D}_{1}$ conducts; energy stored in the inductor gets transferred to the capacitor and the load. One half of a switching period, $\mathrm{Q}_{2}$ also turns on and completes the same cycle similar to $\mathrm{Q}_{1}$ [11-12]. The specification parameters are listed in TABLE I and the simulation results for interleaved boost converter are shown in Figs. 15 and 16.

\section{E. Bidirectional Converter (BDC)}

The bidirectional DC-DC converter along with energy storage is an apt topology for applications such as hybrid vehicle, fuel cell vehicle and renewable energy systems. It not only reduces the cost and improves the efficiency, but also it improves the performance of the system. It also reduces the 
output voltage ripple and input current ripple. Fig.13 shows the equivalent circuit of bidirectional converter.

Fig.14 shows the bidirectional converter connected in parallel with boost converter to reduce the output voltage ripple and input current ripple. Boost converter integrated with BDC will be interfaced with PV and the simulation will be done in MATLAB/SIMULINK. The bidirectional converter modes of operation, design equation, specification parameters are given in [13]. The simulation waveform for the bidirectional converter is shown below.

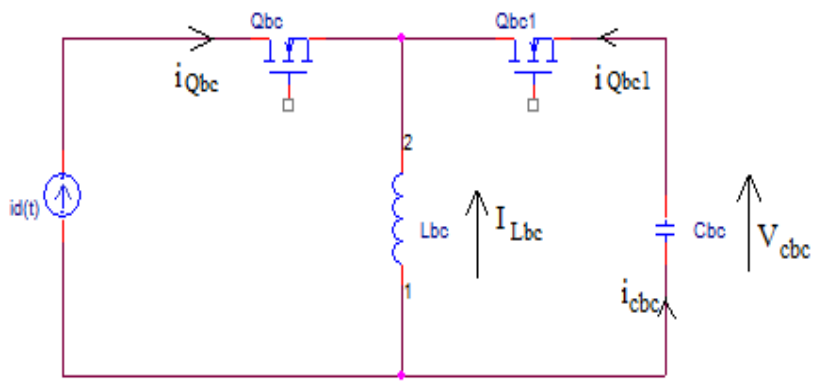

Fig. 13Equivalent Circuit Diagram of Bidirectional Converter

The ripple reduction topologies are studied and analyzed in detail. These two topologies are interfaced with PV and the simulation is carried out in MATLAB/SIMULINK. Fig.15 depicts the simulation waveform of output voltage of interleaved boost converter. Fig. 16 shows the simulation waveform of input current ripple of interleaved boost converter.

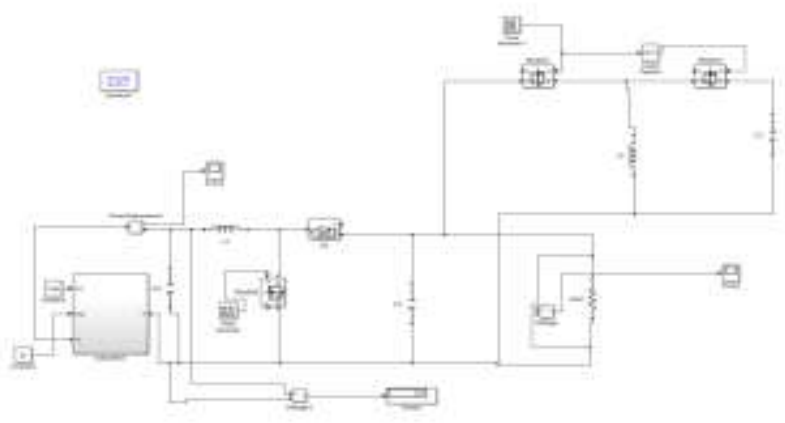

Fig. 14 Simulation of Bidirectional Converter interfaced with PV

Fig. 17 depicts the simulation waveform of output voltage of bidirectional converter. Fig.18 shows the simulation waveform of input current ripple of bidirectional converter. After the simulation is performed, the output voltage ripple and input current ripple were calculated for interleaved boost converter and bidirectional converter. Fig. 19 depicts the comparison of output voltage ripple and input current ripple under different duty cycles for converters interfaced with PV.

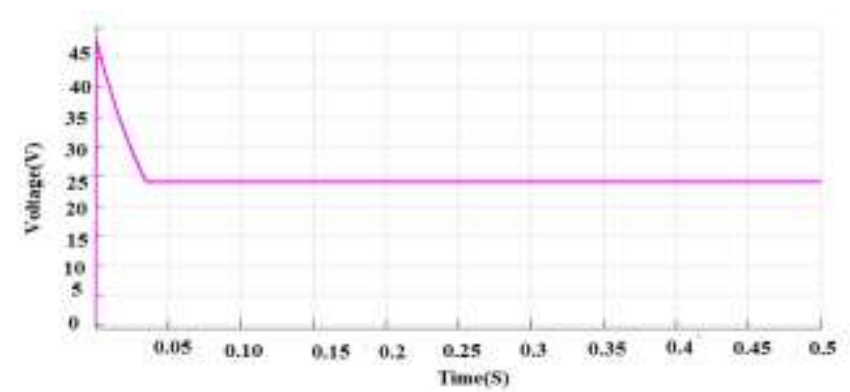

Fig. 15 Simulation waveform of output voltage of interleaved boost converter interfaced with PV

From Fig. 15 it is inferred that the output voltage of interleaved boost converter interfaced with $\mathrm{PV}$ is $24 \mathrm{~V}$.

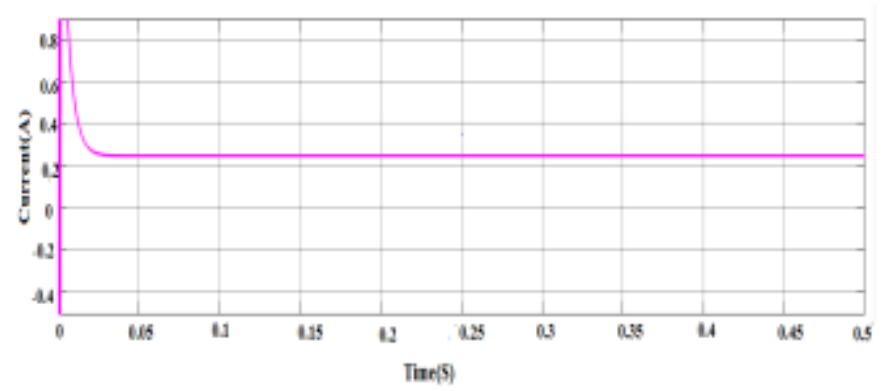

Fig. 16 Simulation waveform of input current of interleaved boost converter interfaced with PV

From Fig. 16 it is inferred that the input current of interleaved boost converter interfaced with PV is $0.24 \mathrm{~A}$.

From Fig. 15 the output voltage ripple for interleaved boost converter is $0.0001 \mathrm{~V}$ and from Fig. 16 the input current ripple for interleaved boost converter is $0.01 \mathrm{~A}$.

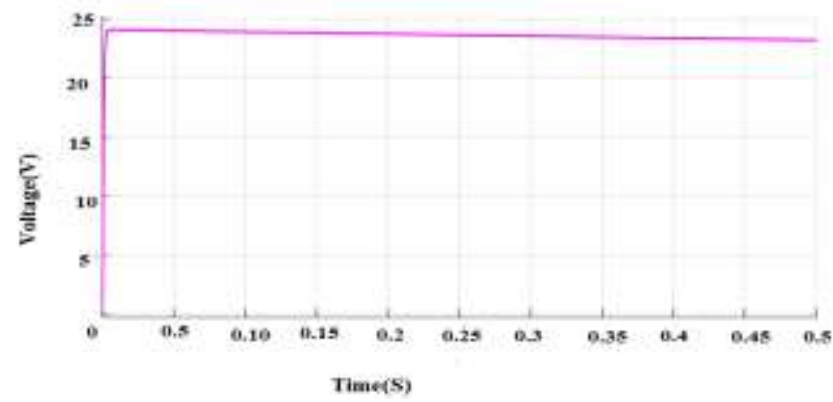

Fig. 17 Simulation waveform of output voltage of bidirectional converter interfaced with PV.

From Fig.17, it is inferred that the output voltage of Bidirectional Converter interfaced with $\mathrm{PV}$ is $24 \mathrm{~V}$. 


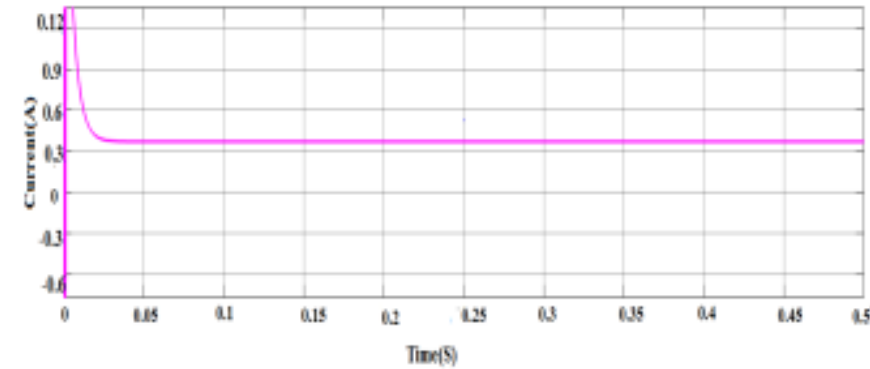

Fig.18 Simulation waveform of input current of bidirectional converter interfaced with PV

From Fig.18, it is inferred that the input current ripple for bidirectional converter interfaced with PV is $0.34 \mathrm{~A}$.

From Fig.17, the output voltage ripple for bidirectional converter is $0.0002 \mathrm{~V}$ and from Fig.18 input current ripple for bidirectional converter is $0.03 \mathrm{~A}$.

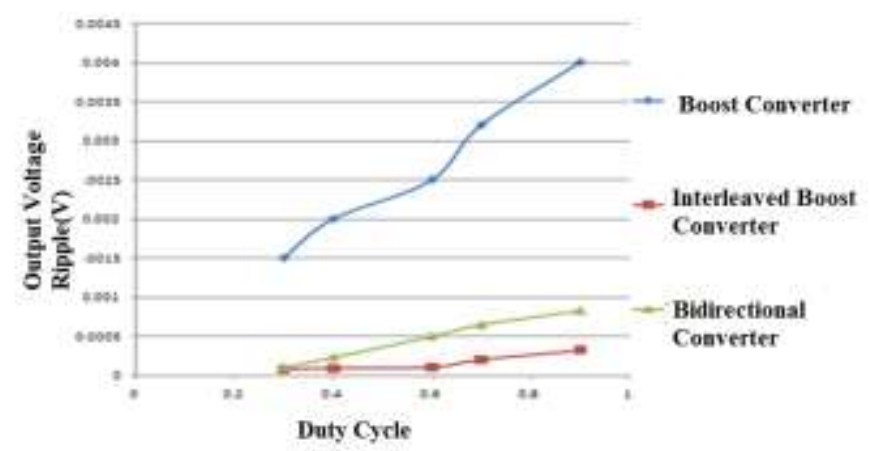

Fig. 19 Input Current Ripple Vs Duty Cycle for ripple reduction technique

From Fig. 19 it is inferred that interleaved boost converter offer less output voltage ripple and input current ripple when compared with other converters interfaced with PV.

\section{CONCLUSION}

In this paper, DC-DC converter topologies were investigated and analyzed in detail. The different DC-DC converters such as Boost converter, SEPIC and NIBB were simulated in MATLAB and the output voltage ripple was calculated. Further to reduce the ripple in Boost converter, ripple reduction topologies such as IBC and boost converter with BDC were investigated. The interleaved boost converter has an output voltage ripple of $0.0001 \mathrm{~V}$ and input current ripple of $0.01 \mathrm{~A}$ and the bidirectional converter has an output voltage ripple of $0.0002 \mathrm{~V}$ and input current ripple of 0.03A.Hence from the ripple reduction topologies and the result analysis, it is concluded that the interleaved boost converter is best suited for PV applications.

\section{ACKNOWLEDGEMENT}

I would like to show my warm thank to my parents, Dr. Mrunal Deshpande who supported me at every bit and without whom it was impossible to accomplish the end task.

\section{VI.REFERENCES}

[1] M. Deepu Vijay, G. Bhuvaneswari, et al, (2015), "LED Based Street Lighting with Automatic Intensity Control using Solar PV", IEEE IAS Joint Individual and Commercial Power System.

[2] Sushmita S. Pandey, V.Patel, (2015), "Review on Recent Applications and International Innovation on Photovoltaics", International Journal of Engineering Research and Development", ISSN.2278-067X.

[3] Frede Blaabjerg, Yongheng Yang, et al, (2014) "Power Electronics- the Key Technology for renewable Energy Systems: International Conference on Ecological Vehicles and Renewable Energies.

[4] Masashi Toyata, Zhi Long Liang, et al, (2013), "Application of Power Electronics Technology to Energy Efficiency and $\mathrm{CO}_{2}$ Reduction.

[5] Soumya Ranjan Behera, Thabir Kumar Meher, (May 2013), "Design of Single Ended Primary Inductor DC-DC Converter". National Institute of Technology,

[6] S.Mariethoz, M.Morari, (2008), "Design and Control of a Buck-Boost DC-DC Power Converter.

[7] B.M.Hansaneen, Adel.A.Elbaset Mohammed, (2008), "Design and Simulation of DC-DC Boost Converter", IEEE Transaction.

[8] Alejandro Oliva, Simon Ang, "Power Switching Converters", (2005) by Taylor and Francis.

[9] J.Leema Rose and B.Sankaragomathi, (2016), "Design, Modeling Analysis and Simulation of a SEPIC Converter", Middle East Journal of Scientific Research, vol-24, pp.2302-2308.

[10] NIBB Converter- Available: https://in.mathworks.com/help/physmod/ sps/examples/buck-boost converter.

[11] G.Bharathi, K.Rajesh, (2017), "Stability Analysis of DCDC Boost Converter For Solar Power Application", International Journal of Ethics in Engineering and Management Education, ISSN: 2348-4748.

[12] Ronald Crews, (2013), “AN-1820 LM5032 Interleaved Boost Converter", Texas Instruments, SNVA335A.

[13] Ramanjaneya Reddy, Beeramangalla Lakshminarasaiah Narasimharaju, (2017) "Single-Stage Electrolytic Capacitor Less Non-Inverting Buck Boost PFC based AC-DC Ripple free LED Driver", IET Power Electronics, Iss-1, no.1,pp.38-4. 